\title{
COMPARISON THE CYTOTOXICITY OF HYDROXYAPATITE MEASURED BY DIRECT CELL COUNTING AND MTT TEST IN MURINE FIBROBLAST NIH-3T3 CELLS
}

\author{
Marica Theiszováa, Soňa Jantováa, Jana Dragúňováb, Petra Grznárováa, Martin Palou
}

a Department of Biochemistry and Microbiology, Faculty of Chemical and Food Technology, Slovak University of Technology, Radlinského 9, SK-81237 Bratislava, Slovak Republic

${ }^{b}$ Central Tissue Bank, University Hospital Ružinov, Ružinovská 6, SK - 82606 Bratislava, Slovak Republic

c Department of Ceramics, Glass and Cement, Faculty of Chemical and Food Technology, Slovak University of Technology, Radlinského 9, SK-81237 Bratislava, Slovak Republic

e-mail: marica.theiszova@stuba.sk

Received: June 10, 2005; Accepted: September 25, 2005

Key words: Hydroxyapatite/Cytotoxicity/Indirect test/Cell proliferation/MTT test/NIH-3T3 Cells

The worldwide growing interest to biomaterials over the last years results from their irreplaceable role in medical clinic. Hydroxyapatite is used in bone reconstruction because of its similar chemical structure compared to the inorganic composition of human bone and it is basic building component of many newly prepared biomaterials. In this study, we evaluated cytotoxic/antiproliferative activity of hydroxyapatite extract using murine fibroblast cell line NIH-3T3 and two in vitro different cytotoxic assays: growth inhibition assay and MTT assay. Hydroxyapatite extract after $72 \mathrm{~h}$ of incubation manifested the significant in vitro cytotoxic/antiproliferative effect only at the highest concentration tested $(100 \%)$. The antiproliferative effect of hydroxyapatite extract at the other concentrations tested $(75 \%$, $50 \%, 25 \%, 10 \%, 5 \%$ and $1 \%$ ) was directly proportional to the concentration and the time of influence. The inhibition of cell proliferation was $86.8-0 \%$. The sensitivity of cell growth inhibition assay (direct counting of viable cells) to the extract influence was higher than that of MTT test.

\section{INTRODUCTION}

The worldwide growing interest to biomaterials over the last years results from their irreplaceable role in medical clinic. Indeed, biomaterials are materials biocompatible and bioactive, intended to interact with biological system, to restore function of defected natural living tissues and organs in human or animal body.

Hydroxyapatite is used in bone reconstruction because of its similar chemical structure compared to the inorganic composition of human bone. In contrast to inert materials, hydroxyapatite develops a direct, adherent and strong bonding with (bone) tissue. This property, called bioactivity, refers to the ability to form a carbonatehydroxyapatite layer at the material surface. This material subsequently recruits bone producing cells (osteoblasts) which differentiate and produce bone matrix on the newly formed apatite. Hydroxyapatite can be made porous/dense, resorbable/solid and it can be produced in powders/blocks ${ }^{1}$. Bone is a complex material composed of proteins, mainly collagen, with hydroxyapatite, therefore, now many investigations are focused on the hybrid biomaterials of hydroxyapatite with proteins and other synthetic polymers ${ }^{2}$.

Biomaterials may have low, medium or high potential risk to human safety, depending on the type and extent of patient contact. One of the recommended and appropriate step for the biological assessment of medical devices is in vitro assessment of cytotoxicity of new biomaterials.
In this primary screening we evaluated cytotoxicity of hydroxyapatite by indirect test on the murine fibroblast cell line NIH-3T3.

\section{MATERIAL AND METHODS}

The murine fibroblast cell line NIH-3T3 was obtained from American Type Culture Collection, Rockville, MD, USA. The cells were cultured in supplemented Dulbecco's minimal Eagle medium (DMEM) at $37^{\circ} \mathrm{C}$ in a humidified atmosphere containing $95 \%$ air and $5 \% \mathrm{CO}_{2}$. The cells were subcultivated two to three times a week and cell growth and viability were assessed by $0.4 \%$ trypan blue staining. An extract of hydroxyapatite was obtained after 3 days of incubation on a reciprocal shaker in $15 \mathrm{ml}$ of culture medium without foetal calf serum under sterile condition in a termostat at $37^{\circ} \mathrm{C}$. At the end of the incubation, the undiluted ( $100 \%)$ extract of the hydroxyapatite was filtred $(0.2 \mu \mathrm{m})$ and diluted extracts of the concentrations $1,5,10,25,50,75$ to $100 \%$ were prepared.

Hydroxyapatite was synthesized by sol gel process from $\mathrm{Ca}\left(\mathrm{NO}_{3}\right)_{2} \cdot 4 \mathrm{H}_{2} \mathrm{O}$ (A.R) and (NH) $\mathrm{HPO}_{4}$ (A.R) dissolved in deionized water at $\mathrm{pH}$ brought up to 11 by adding ammonium hydroxide following equation:

$$
\begin{aligned}
5 \mathrm{Ca}\left(\mathrm{NO}_{3}\right)_{2} \cdot 4 \mathrm{H}_{2} \mathrm{O}+ & 3\left(\mathrm{NH}_{4}\right)_{2} \mathrm{HPO}_{4}+4 \mathrm{NH}_{3}= \\
& =\mathrm{Ca}_{5}\left(\mathrm{PO}_{4}\right)_{3} \mathrm{OH}+10 \mathrm{NH}_{4} \mathrm{NO}_{3}+3 \mathrm{H}_{2} \mathrm{O}
\end{aligned}
$$


Then, the gel was annealed at $600{ }^{\circ} \mathrm{C}$ and sintered at $800{ }^{\circ} \mathrm{C}$ and $1100{ }^{\circ} \mathrm{C}$. Sintered samples of hydroxyapatite were milled and used to cytotoxic study.

All other chemicals were obtained from Sigma Chemicals (St Louis, MD).

Indirect test. Cytotoxicity of hydroxyapatite extract was measured by the cell growth inhibition assay. Antiproliferative activity of the extract was performed in 96-well plates. NIH-3T3 cells were plated at 15000 cells per well in 96-well plates in $200 \mu 1$ of culture medium and were incubated at $37^{\circ} \mathrm{C}$. After $24 \mathrm{~h}$ of incubation, when the cultures were at sub-confluence, the medium was removed; the NIH-3T3 cell monolayer was washed with PBS and exposed to $200 \mu \mathrm{l}$ of the extract for $24 \mathrm{~h}$. Each concentration was tested in three wells together with appropriate controls. At the end of treatment, cells were harvested by $0.25 \%$ trypsin, and later resuspended. Cell growth and viability were assessed by direct counting of $0.4 \%$ trypan blue dye-excluding cells.

Indirect effect of hydroxyapatite extract on morphology of $N I H-3 T 3$. The effect of hydroxyapatite extract on morphology of untreated and treated NIH-3T3 cells was assessed by the light microscopy and then photographed by SONY CYBER-SHORT 3.2.

MTT test. After $24 \mathrm{~h}$ of cell culturing in the presence of hydroxyapatite extract, the medium was removed and $100 \mu$ of growth medium with MTT $(5 \mathrm{mg} / \mathrm{ml}$ in PBS $)$ was added to the cultures. Cells were incubated at $37^{\circ} \mathrm{C}$ in humidified atmosphere for $3 \mathrm{~h}$. Then the growth medium was removed, $100 \mu$ of ethanol was added to each well to dissolve purple crystals of formazan. The absorbance was measured in a spectrophotometer at a wavelength of $540 \mathrm{~nm}$. Reported values are the means of three replicates and are expressed as percentages of the control values.

\section{RESULTS AND DISCUSSION}

During the last years, the interest of in vitro systems, as an alternative to animal experiments in toxicological research has been steadily increasing. Cytotoxicity is the harmful or noxious unwanted effect induced by a biomaterial in cell culture system in vitro. Cytotoxicity testing includes numerous methods, both qualitative and quantitative. In this study we used indirect test, in which the rate of cell growth (cell number) and the metabolic activity (MTT) have indicated the degree of cytotoxicity of hydroxyapatite extract.

The growth of NIH-3T3 cells exposed to hydroxyapatite extract concentrations ranging from $100 \%-1 \%$ was monitored within $72 \mathrm{~h}$ of culturing (Fig. 1). As shown in figure, the addition of extract to the medium reduced NIH-3T3 viable cell number. After 24 h, five tested concentrations had an acute cytotoxic effect manifested by total growth inhibition (concentrations of $1 \%, 5 \%$ and $10 \%$ ) or $22 \%-54 \%$ degeneration of cell populations

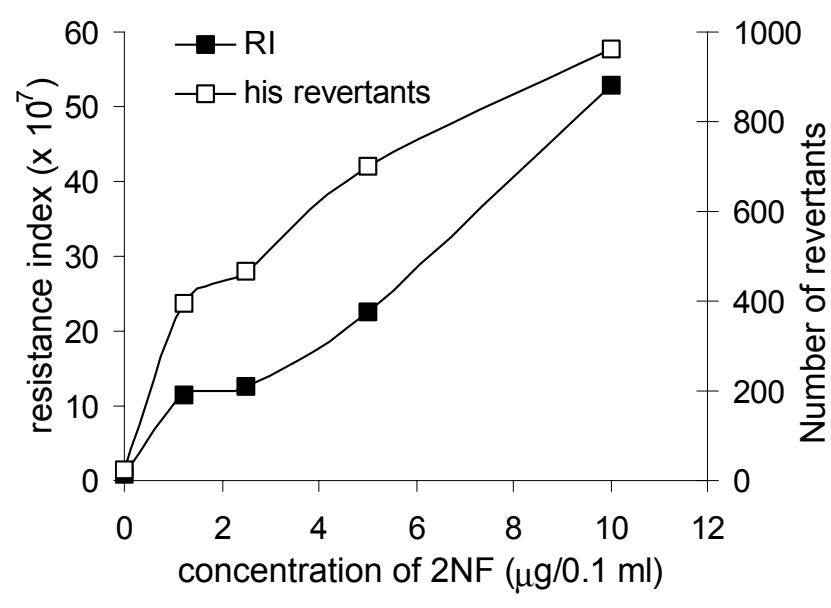

Fig. 1. Growth curve of the NIH-3T3 cells treated by 3 day extract of hydroxyapatite in the course of $72 \mathrm{~h}$. Each point represents the mean \pm s.d. of three experiments. s.d. is $<10 \%$.

(concentrations of $25 \%, 50 \%, 75 \%$ and $100 \%$ ). On the other hand, in the next $48 \mathrm{~h}$ time interval the NIH-3T3 cells treated with the extract concentrations of $75 \%, 50 \%$, $25 \%$ and $10 \%$ manifested $2.7-72.2 \%$ of cell growth. The extract concentration of $100 \%$ induced cytolytic effect during the whole experiment. The growth of the NIH3T 3 cells treated with the extract concentrations of $5 \%$ and $1 \%$ was 41.4 and $94.2 \%$. These changes in viable cell number were also observed when aliquots of the cultures were examined by light microscopy (Fig. 2). The control cells (Fig. 2a) grew on the surface of cultivation slide and during $72 \mathrm{~h}$ of incubating a monolayer was formed. Figures 2 b, c, d, e, f, g, h show significant morphology and cell number changes which occurred within $72 \mathrm{~h}$ of the extracts influence.

The effects of hydroxyapatite extracts on NIH-3T3 viability measured by MTT test are shown in Fig. 3. MTT is a yellow water-soluble tetrazolium dye which is reduced by live cells to a purple formazan product insoluble in aqueous solutions. The amount of formazan generated is directly proportional to the number of viable cells. As can be seen from Fig. 3, hydroxyapatite extract during $72 \mathrm{~h}$ of incubation induced $66.3-0 \%$ inhibition of celular viability in comparison to the control. The highest effect was induced with $100 \%$ extract concentration (viability inhibition of $66.3 \%-59.1 \%$ ), the weakest activity was found with $1 \%$ extract concentration (viability inhibition of $12.3 \%-0 \%$ ).

In the present work, both methods, rate of growth and the metabolic activity have indicated the different degree of toxicity of hydroxylapatite extract. The sensitivity of cell growth inhibition assay (direct counting of viable cells) to the extract influence was higher than that of MTT test. This discrepancy has been reported also by other autors ${ }^{3,4}$ and it may be due to the differences in the principles of used methods. 

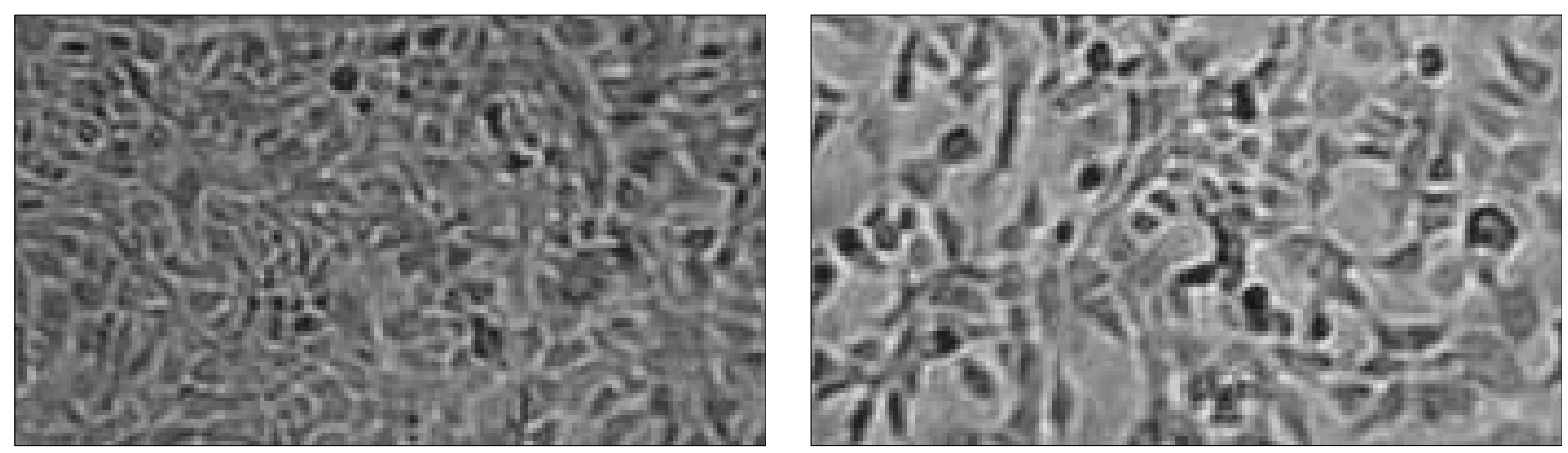

a

$\mathrm{b}$
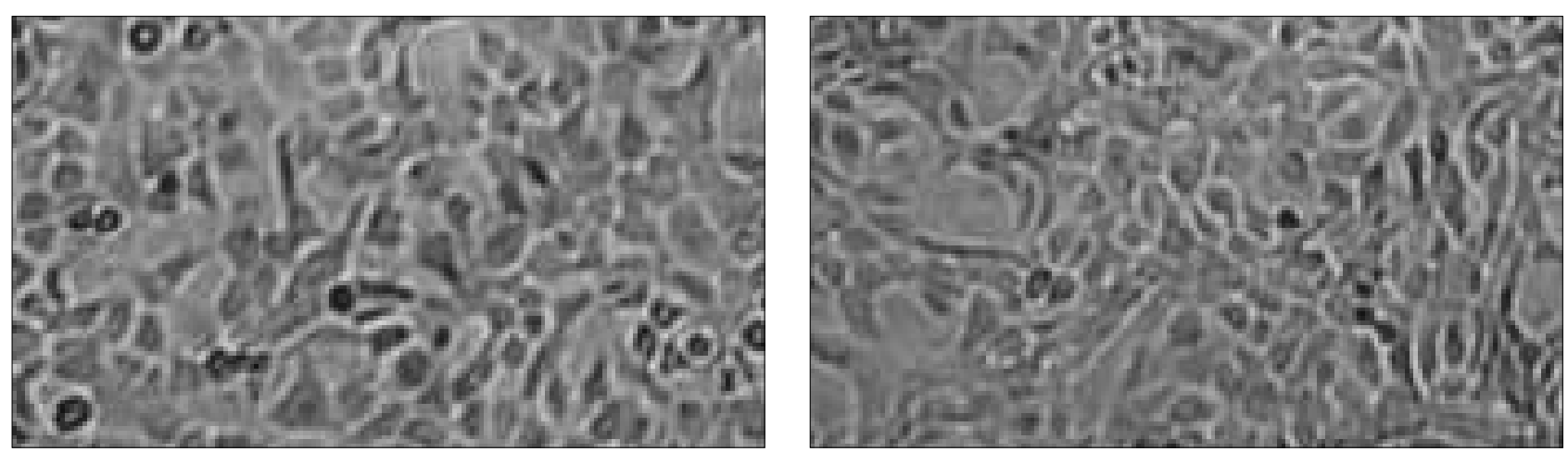

C

$\mathrm{d}$
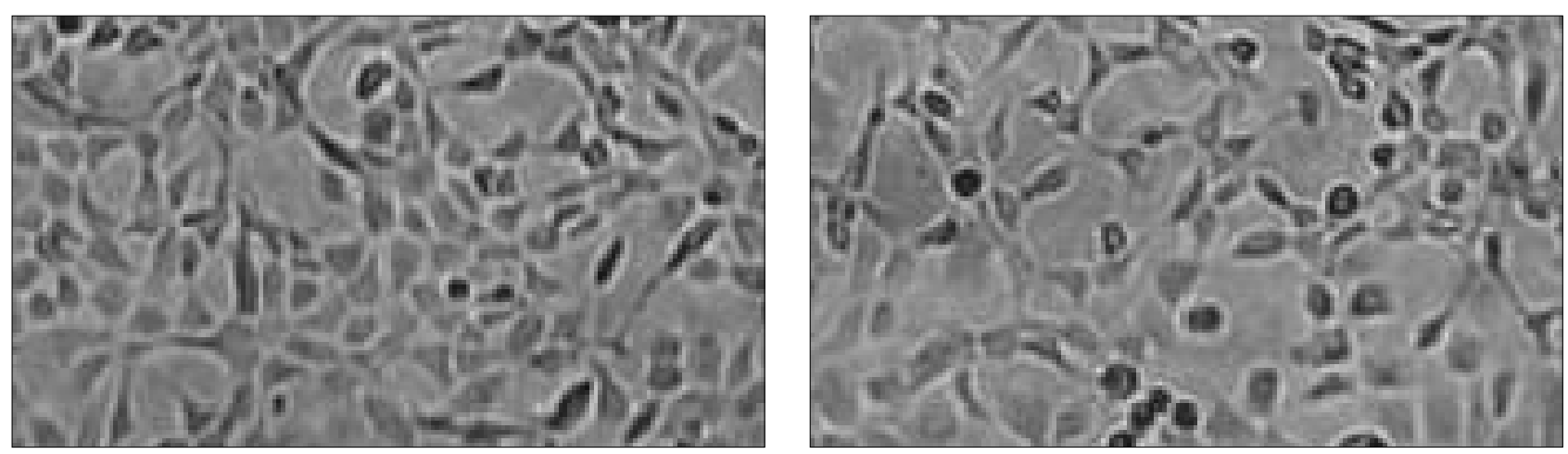

e

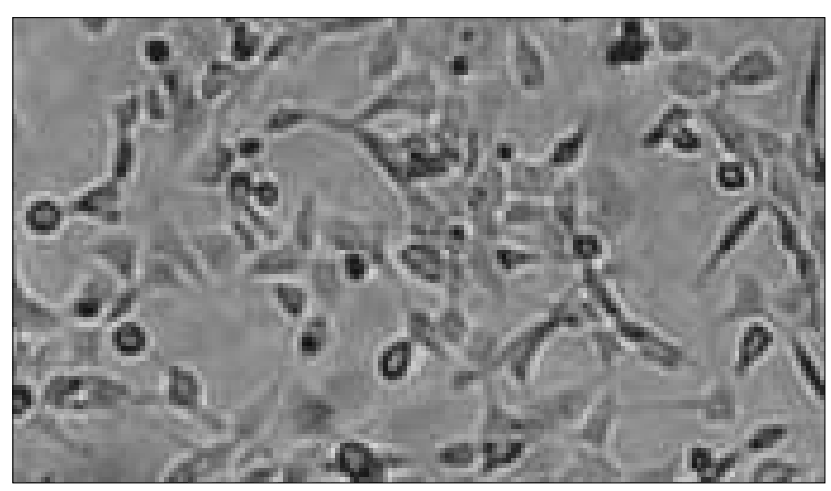

f

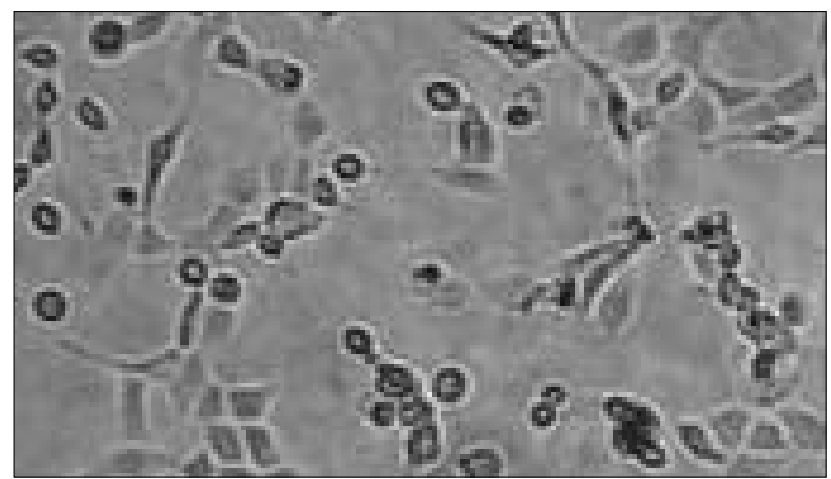

g

$\mathrm{h}$

Fig. 2. Morfology of the NIH-3T3 cells treated by 3 day extract of hydroxyapatite after $72 \mathrm{~h}$ incubation. Concentration of extract (\%): a) Control; b) 1 ; c) 5; d) 10; e) 25; f) 50; g) 75; h) 100. 
Based on results obtained here we can conclude that hydroxyapatite extract after $72 \mathrm{~h}$ of incubation manifested the significant in vitro cytotoxic/antiproliferative effect only at the highest tested concentration (100\%). The sensitivity of cell growth inhibition assay (direct counting of viable cells) to the extract influence was higher than that of MTT test.

Results from screening tests that are made at the cell level we have to consider for orientational and we can not transfer them mechanically to the man.

\section{ACKNOWLEDGEMENT}

This study was supported by the Science and Technology Assistance Agency under the contract No. APVT 20-015904.

\section{REFERENCES}

1. Rosengren A (2004) Cell-protein-material Interactions on Bioceramics and Model Surfaces. Acta Universitatis Upsaliensis, p. 30 .

2. Tachibana A, Kaneko S, Tanabe T et al. (2005) Rapid fabrication of keratin-hydroxyapatite hybrid sponges toward osteoblast cultivation and differentiation, Biomaterials 26, 297-302.

3. Tanaka N, Asakura M, Hattori Ch, Hayasaka A, Hayashi M. (1998) Validation study on five cytotoxicity assays by Jsaae - IV. Details of the colony formation assay. AATEX 5, 74-86.

4. Perkins MA, Osborne R, Rana FR, Ghassemi A, Robinson MK. (1999) Comparison of in vitro and in vivo human skin responses to consumer products and ingredients with a range of irritancy potencial. Toxicol Sci 2, 218-229.

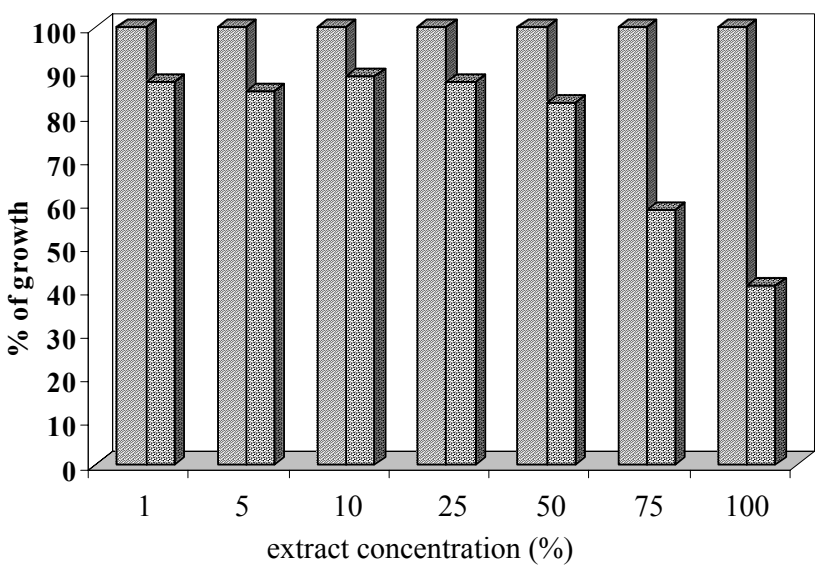

Fig. 3. Effect of diluted $(1 \%, 5 \%, 10 \%, 25 \%, 50 \%$ and $75 \%)$ and undiluted 3 day extract (100\%) of hydroxyapatite on cell viability of the NIH-3T3 cells obtained after $72 \mathrm{~h}$ by MTT test. The data are expressed as a percentage of the untretaed cells. Each point represents the mean \pm s.d. s.d. is $<10 \%$. 